\title{
Functional changes in transcriptomes of the prefrontal cortex and hippocampus in a mouse model of anxiety
}

\author{
Dezso P. Virok ${ }^{1 *}$, Zoltán Kis ${ }^{2 \star}$, Viktor Szegedi ${ }^{1}$, Gábor Juhász ${ }^{3}$, Ágnes \\ Zvara², Jr., Géza Müller ${ }^{4}$, György Lévay ${ }^{4}$, László G. Hársing ${ }^{5}$, Róbert \\ Rajkó ${ }^{6}$, Botond Penke ${ }^{1,3}$, Zoltán Janka7, Tamás Janáky³ , László G. Puskás² \\ ${ }^{1}$ Institute for Plant Genomics, Human Biotechnology and Bioenergy (BAY-GEN), 6726 Szeged Derkovits fasor 2., \\ Hungary \\ ${ }^{2}$ Laboratory for Functional Genomics, Biological Research Center, Hungarian Academy of Sciences, 6726 Szeged \\ Temesvári krt. 62., Hungary \\ ${ }^{3}$ Department of Medical Chemistry, University of Szeged, 6720 Szeged Dóm tér 8., Hungary \\ ${ }^{4}$ EGIS Nyrt., 1106 Budapest Keresztúri út 30-38. Budapest, Hungary \\ ${ }^{5}$ Institute of Pharmacology and Pharmacotherapy Semmelweis University, 1085 Budapest VIII. Üllöi út 26., Hungary \\ ${ }^{6}$ Faculty of Engineering, University of Szeged, 6725 Szeged, Moszkvai krt. 5-7., Hungary \\ ${ }^{7}$ Department of Psychiatry, University of Szeged, 6725 Szeged, Semmelweis u. 6., Hungary
}

Correspondence: Dezso P. Virok, e-mail: virok@mlab.szote.u-szeged.hu

\begin{abstract}
:
Anxiety is a multi-etiology disorder influenced by both genetic background and environment. To study the impact of a genetic predisposition, we developed a novel mouse model of anxiety using a combination of crossbreeding and behavioral selection. Comparison of the transcriptomes from the prefrontal cortex and hippocampus of anxious and control mice revealed that the numbers of significantly up- and down-regulated genes were modest, comprising approximately $2 \%$ of the tested genes. Functional analysis of the significantly altered gene sets showed that functional groups such as nervous system development, behavior, glial cell differentiation and synaptic transmission were significantly enriched among the up-regulated genes, whereas functional groups such as potassium ion transport, Wnt signaling and neuropeptidergic signaling were significantly enriched among the down-regulated genes. Many of the identified genes and functional groups have been previously linked to the molecular biology of anxiety, while several others, such as transthyretin, vasoactive intestinal polypeptide and various potassium ion channels, are novel or not as well described in this context. Supporting the gene expression data, we also found increased excitability in the hippocampi of anxious mice, which can be a phenotypic result of decreased potassium channel density. Our transcriptome screen showed that the initiation and/or effect of anxiety involve multiple pathways and cellular processes. The identified novel genes and pathways could be involved in the molecular pathogenesis of anxiety and provide potential targets for further drug development.
\end{abstract}

\section{Key words:}

anxiety, gene expression, microarray, mouse model, hippocampus, prefrontal cortex

\footnotetext{
* These authors contributed equally
} 


\begin{abstract}
Abbreviations: ACE - angiotensin convertase enzyme, ACSF - artificial cerebrospinal fluid, ADCYAP1 - adenylate cyclaseactivating polypeptide $1, \mathrm{AX}$ - anxious, $\mathrm{C}$ - control, cAMP cyclic adenosine monophosphate, CARTPT - cocaine and amphetamine-regulated transcript, CGRP - calcitonin-gene related peptide, CREB - cAMP response element binding, fEPSP - field excitatory post synaptic potential, GO - gene ontology, GRIA1 - glutamate receptor, ionotropic 1, GRM1 - glutamate receptor, metabotropic 1, GRP - gastrin releasing peptide, KCNB1 - potassium voltage-gated channel, Shab-related subfamily, member 1, KCNJ4 - potassium inwardly-rectifying channel, subfamily J, member 4, KCNQ5 - potassium channel, voltage gated, KQT-like subfamily, member 5, MAPK - mitogen-activated protein kinase, MEA - multi electrode array, NPY - neuropeptide Y, NT - neurotensin, PDYN - prodynorphin, PENK - proencephalin, PCx - prefrontal cortex, QPCR quantitative real-time PCR, TBS - theta-burst stimulation, VIP - vasoactive intestinal polypeptide
\end{abstract}

\section{Introduction}

Anxiety spectrum disorders exhibit a high prevalence and have a serious medical and socioeconomic impact in developed countries $[2,21]$. The disease is multifactorial, requiring an interplay between genetic and environmental factors. The genetic background of anxiety has been demonstrated to be polygenic, most likely involving genes from different cellular processes and pathways $[53,58]$. The identification of the individual genes related to anxiety is a challenging task due to the complex gene interactions that finally lead to the disease. This complexity is mirrored by the fact that anxiolytic drugs are effective only in a certain proportion of patients; approximately $40 \%$ of those treated have limited or no response to these therapies [16]. Above the molecular organizational level, the anxiety-related neural circuits are also complex, involving the prefrontal cortex (PCx), thalamus, the hypothalamic-pituitary-adrenal axis, amygdala and hippocampus. While the amygdala is central in the formation of emotional responses, especially fear, two other regions, the hippocampus and ventromedial and dorsomedial $\mathrm{PCx}$, are preferentially involved in the contextualization of the proposed threat and the learning of aversive behavior [3].

The genetic complexity of the disease, the inherent biological variability of human patients, and the difficulties in collecting human brain samples make it difficult to study the molecular mechanisms underlying anxiety. Although animals can only mimic certain domains of the anxiety-related complex behavioral phe- notypes seen in humans, the availability of animal tissues and the low genetic variability of inbred mouse or rat strains make animal models attractive. The selection and crossbreeding of extreme anxiety-related phenotypes could result in a relatively homogenous population in which the anxiety-related behavior is a consequence of the same or similar alterations in the molecular and neuronal networks of the brain. Accordingly, we applied a behavioral selection strategy to construct an animal model in which the mice with extreme anxiety phenotypes were selected and crossbred. Selection was made on the basis of anticipatory anxiety behavior during the handling procedure. When mice were moved to another cage, some individuals always 'volunteered' earlier, while others always moved away from the experimenter. Animals were separated into two groups, early movers (nonanxious, control) and late movers (anxious, AX), and were inbred. After 35 generations, the selected AX breed displayed significant anxiety relative to the non-anxious controls in different well-established anxiety tests, such as the open field, elevated plus maze and light dark tests [54]. The complex nature of anxiety requires complex, generally open systems in order to explore the underlying molecular networks. DNA microarray technology has been proven to be highly efficient in describing molecular networks in complex biological processes, such as development, immunity, cancer progression [35] and various psychiatric disorders [37]. We used DNA microarrays to study the anxiety related transcriptome changes in two relevant brain regions, the $\mathrm{PCx}$ and hippocampus, of AX and control mice. We found several genes and gene networks that were differentially expressed in one or both of the studied regions. Several of the identified genes have been shown previously to be involved in anxiety, while others are new and could provide valuable targets for future drug discovery.

\section{Materials and Methods}

\section{Animal care and handling}

Individuals of a non-commercially available inbred mouse strain (MG15) were maintained at EGIS Pharmaceuticals Co. (Budapest, Hungary). Mice from the MG15 strain were crossed with NMRI mice (Charles River Ltd., Budapest, Hungary), resulting a new 
strain. The behavioral selection was performed on individuals of this strain as described previously [54]. Experiments were performed on $12 \mathrm{AX}$ and 12 control male mice 15-17-weeks old. The animals were kept and the experiments were conducted in conformity with Council Directive 86/609/EEC, the Hungarian Act of Animal Care and Experimentation (1998, XXVIII) and local regulations for the care and use of animals for research.

\section{RNA preparation, amplification and labeling}

Total RNA was purified from each mouse sample (PCX and hippocampus tissue from each mouse) using an RNA purification kit (Macherey Nagel, Düren, Germany) according to the manufacturer's instructions. At a final concentration of $0.8 \mathrm{U} / \mu 1$, an RNase inhibitor (Fermentas, Lithuania) was added to the samples. RNA quantity was determined using NanoDrop 3.1.0. RNA samples were stored at $-80^{\circ} \mathrm{C}$ before used. A sample of the total RNA $(1 \mu \mathrm{g})$ was amplified with the AminoAllyl MessageAmpTM II aRNA Amplification Kit (Ambion, USA) according to the manufacturer's instructions. An aliquot of the aminoallyl-modified amplified RNA (aRNA; $6 \mu \mathrm{g}$ ) was labeled with either Cy5 or Cy3 dye according to the manufacturer's instructions (Ambion, USA) then purified using RNA purification columns from Macherey Nagel (Düren, Germany). The dye incorporation rate and the labeled aRNA concentration were detected using NanoDrop 3.1.0. The incorporation rate of the samples was 30-60 dye molecules per 1000 nucleotides.

\section{Microarray hybridization and data analysis}

The mouse oligonucleotide microarray $(8 \times 15,000$ format) from Agilent Technologies Inc. (Santa Clara, CA, USA) was used to determine gene expression changes. The hybridization was performed with the Agilent Gene Expression Hybridization kit according to the manufacturer's instructions. Each array was scanned at $543 \mathrm{~nm}$ (for Cy3 labeling) or at $633 \mathrm{~nm}$ (for Cy5 labeling) in the Agilent Scanner using the Extended Dynamic Range function of the ScanArray software (10\% and $100 \%$ photomultiplier values). Twelve different samples from either the hippocampus or the PCX (AX and control) were pooled into four groups (three RNA samples each) and regarded as biological replicas. In order to eliminate any distortion caused by the different fluorescent dyes, parallel dye-swap experiments were carried out from two pools and regarded as technical replicas. Raw data were analyzed with the Feature Extraction software from Agilent Technologies (ver. 9.5.1.1.) and the two-color gene expression protocol (GE2_v5_95 Feb07). All the ratios were normalized using the Lowess normalization method. The two-tailed twosample unequal variance Student's $t$-test with a twofold change cutoff was applied to determine which genes showed significantly altered expression levels (GeneSpring GX 10.0.2.). The MIAME formatted microarray data can be found in the ArrayExpress Archive (http://www.ebi.ac.uk/microarray-as/ae/) with the Accession Number: E-MEXP-2603. For functional analysis of the altered genes, Gene Ontologybased functional grouping was applied using the DAVID web-based knowledge database [51]. The Pathway Studio 6.0 (Rockville, MD, USA) and the STRING web-based software [27] were used for pathway and network analysis.

\section{Quantitative real-time PCR (QPCR)}

In order to validate the microarray data, QPCR was performed on a RotorGene 3000 (Corbett Research, Sydney, Australia) using gene-specific primers and the SybrGreen protocol (Roche Applied Science, Mannheim, Germany) as described previously [42]. Melting temperature analysis was done after each reaction to check the quality of the reaction. Relative expression ratios were calculated as normalized ratios to the mouse $\beta$-actin gene. A control sample without template was used for each PCR run to check for dimer formation in the primers. The final relative gene expression ratios were calculated as $\Delta-\Delta \mathrm{Ct}$ values.

\section{Electrophysiology}

Using standard procedures, 350- $\mu \mathrm{m}$-thick transverse hippocampal slices were prepared from the brains of 2.5-month-old mice using a McIlwain tissue chopper (Campden Instruments, Loughborough, UK). Slices were incubated in standard artificial cerebrospinal fluid (ACSF) at ambient temperature for $60 \mathrm{~min}$ with $95 \% \mathrm{O}_{2}-5 \% \mathrm{CO}_{2}$. The composition of the ACSF was as follows (mM): $\mathrm{NaCl}, 130 ; \mathrm{KCl}, 3.5 ; \mathrm{CaCl}_{2}, 2$; $\mathrm{MgCl}_{2}, 2 ; \mathrm{NaH}_{2} \mathrm{PO}_{4}, 0.96 ; \mathrm{NaHCO}_{3}, 24 ; \mathrm{D}$-glucose, 10 ( $\mathrm{pH}$ 7.4). Individual slices were transferred to a 3Dmulti-electrode array (MEA) chip with 60 tip-shaped, 60 - $\mu \mathrm{m}$-high electrodes spaced at $100 \mu \mathrm{m}$ (Ayanda 
Fig. 1. Experimental design for microarray analysis. Twelve animals each were sacrificed from the $A X$ and control groups. Individual total RNA samples from the PCx and the hippocampus were pooled so that one poo contained RNAs from three animals. For each brain region, four pooled samples were tested from AX mice against four pooled samples from control mice. To control dye bias, a dye swap was also incorporated in the experimental design. Two of the four hybridizations were performed with Cy5 (red)-labeled AX samples, and the other two were performed with $\mathrm{Cy}_{3}$ (green)-labeled AX samples (Fig. 1) HIPPO: hippocampus

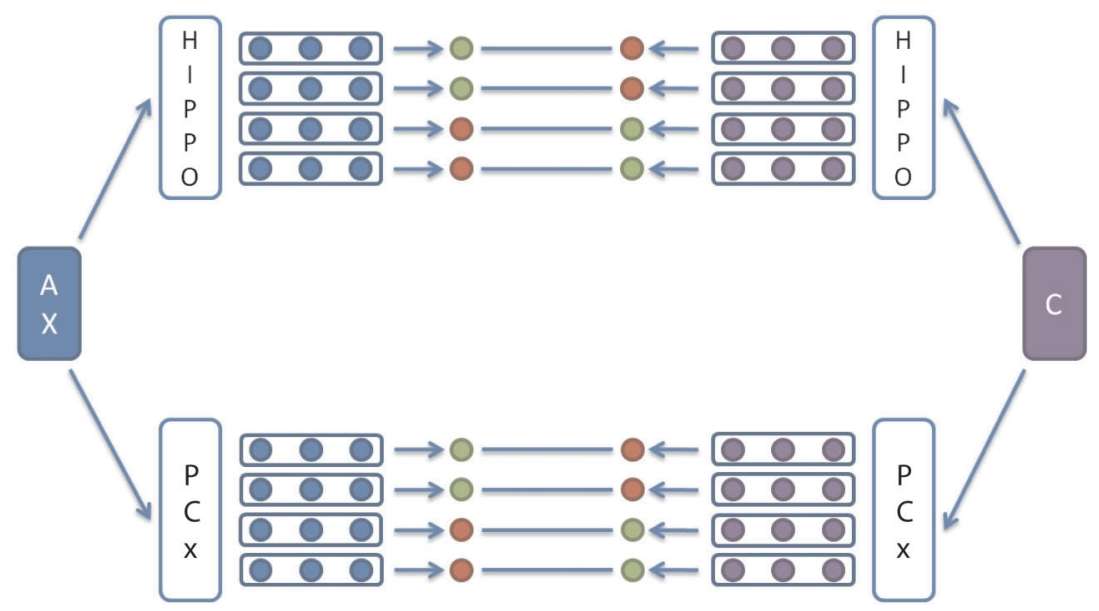

Biosystems, S.A., Lausanne, Switzerland). The slice was continuously perfused with oxygenated ACSF $\left(1.5 \mathrm{ml} / \mathrm{min}\right.$ at $\left.34^{\circ} \mathrm{C}\right)$ throughout the recording session. Data were recorded using a standard, commercially available MEA setup (Multi Channel Systems MCS GmbH, Reutlingen, Germany). The Schaffercollateral was stimulated by injecting a biphasic current waveform $(-100 /+100 \mu \mathrm{s})$ through one selected electrode at $0.033 \mathrm{~Hz}$. Care was taken to place the stimulating electrode in the same region from one slice to the other. The peak-to-peak amplitudes of field excitatory postsynaptic potentials (fEPSP) at the stratum pyramidale and stratum radiatum of CA1 were analyzed. After a $30 \mathrm{~min}$ incubation period, the threshold and the maximum of the stimulation intensity required to evoke responses was determined. For evoking responses, $30 \%$ of the maximal stimulation intensity was used. Following a stable 15-min control sequence, the stimulus intensity was continuously increased from 0 to $70 \mu \mathrm{A}$ in $10 \mu \mathrm{A}$ steps (Input/Output curve). Long-term potentiation (LTP) was induced using a theta-burst stimulation (TBS, $4 \times 10$ bursts of 4 pulses at $100 \mathrm{~Hz}$ ) protocol applied at the maximum stimulation intensity.

\section{Results}

\section{Microarray analysis of the PCx and hippocam- pus transcriptomes in $\mathrm{AX}$ and control mice}

Twelve animals were sacrificed from the AX and control groups for transcriptome analysis. Total RNAs were extracted from the hippocampus and $\mathrm{PCx}$ and pooled so that each pool contained RNAs from 3 animals. For each brain region, four pooled samples from AX mice were compared to four pooled samples from control mice. A dye swap was also incorporated in the experimental design. Two of the four hybridizations were performed with Cy5 labeled AX samples, and the other two were performed with $\mathrm{Cy} 3$ labeled $\mathrm{AX}$ samples (Fig. 1). Approximately 15,000 genes from the transcriptomes of the two brain regions were investigated using a custom made Agilent oligo microarray with 15,000 features. In order to obtain reliable microarray data, a two-step statistical analysis was performed. A two-tailed two-sample unequal variance Student's $t$-test was used to determine the $p$ value that was used to find the significant gene expression changes. Gene expression ratios with $\mathrm{p}$ value $<0.05$ and an $\mathrm{AX} /$ control ratio $<-2$ or $>2$ were regarded as significant repression or over expression, respectively, in gene activity. To assess the false discovery rate, the microarray data were also investigated with the Significance Analysis of Microarray method (SAM) using the MultiExperiment Viewer software [45]. The analysis showed that $94 \%$ and $99 \%$ of the hippocampus genes and $72 \%$ and $84 \%$ of the PCx genes that were identified as significant by our statistical analysis were also significantly changed using SAM with a false discovery rate of $5 \%$ and $10 \%$, respectively.

The numbers of significantly up regulated genes in the AX mice compared to controls were similar in the two brain regions. Sixty and 51 unique genes were found to be up-regulated in the PCx and hippocampus, respectively, and 97 genes were up-regulated in 
A
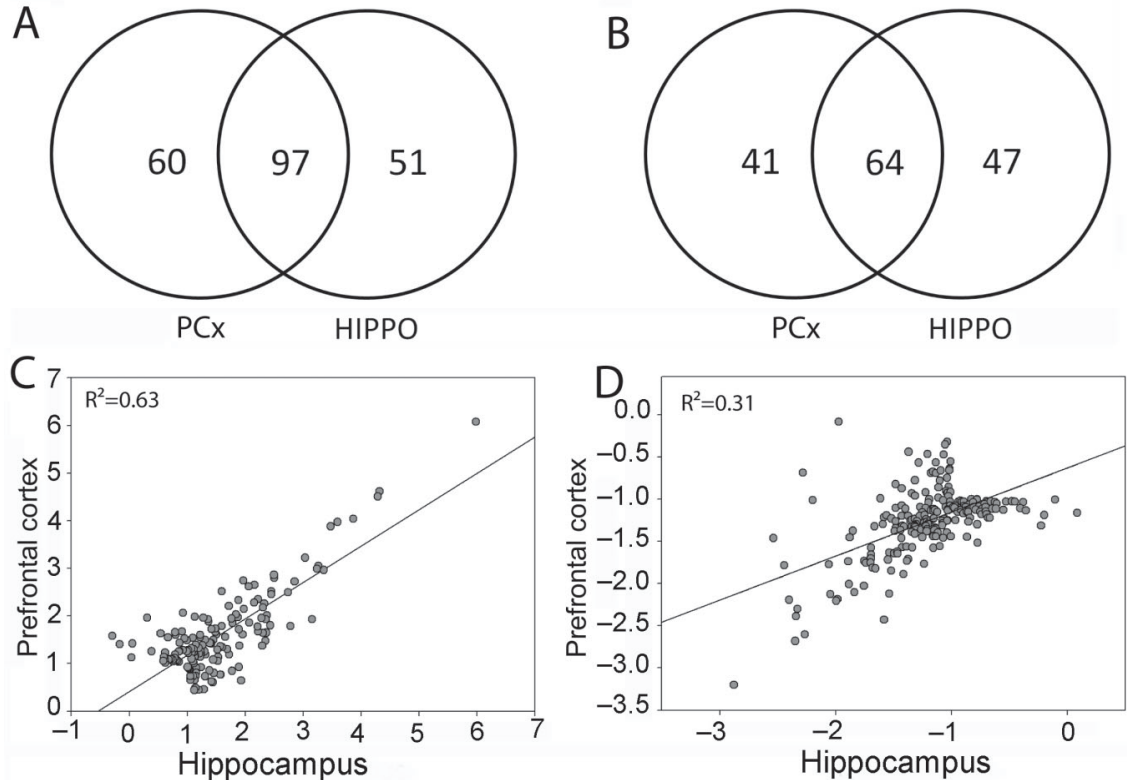

Fig. 2. Comparison of transcriptome changes in the PCx and hippocampus. Venn diagram of the $(\mathbf{A})$ significantly up-regulated and (B) downregulated genes in the $\mathrm{PC} x$ and hippocampus (HIPPO). Correlation between the average $\log _{2}$ ratios of $(\mathbf{C})$ induced and (D) repressed genes in AX PCX and hippocampus $v s$. the control brain regions both regions (Fig 2A). The numbers of downregulated genes were also similar in the two brain regions: 41 and 47 unique genes were found to be down-regulated in the PCx and hippocampus, respectively, and 64 genes were repressed in both regions (Fig. 2B). The pattern of gene expression was similar in the two brain regions. We observed a relatively high correlation ratio of 0.63 between the upregulated genes in the two brain regions, suggesting that the direction and extent of up-regulation was not region-specific in the AX brain (Fig. 2C). The patterns of down-regulation in the brain regions were less correlated, although the observed correlation coefficient of 0.31 showed that at least the direction of down-regulation was similar in the two regions. None of the genes were up-regulated in one region and down-regulated in the other (Fig. 2D).

To validate the microarray data, the same RNA samples that were used for microarray analysis were used for an extensive QPCR screen. Altogether, 66 and 68 significantly changed genes detected by microarray were tested by QPCR in the PCx and hippocampus. Comparing the microarray and the QPCR data, the results demonstrated a convincing 0.81 correlation between the two methods. Moreover, of the 134 genes tested, only two ( $1.49 \%$ false positive) demonstrated expression changes in opposite directions in the microarray and QPCR (Fig. 3 A, B).

\section{Functional analysis of microarray data}

In order to gain information about the general functions of the altered genes, we performed a Gene Ontology (GO) analysis, using the DAVID web-based knowledgebase [51]. Generally, DAVID analyzes the GO terms relating to the significantly altered genes, identifies the terms that contain multiple genes, and calculates a significance value for the observed enrichment in comparison with a background gene set. Because the directions of gene alterations were generally similar in the two regions and many altered genes were shared, we analyzed the up- and down-regulated genes in toto from both brain regions. The analysis revealed that several of the GO biological function groups that were significantly enriched in the $\mathrm{AX}$ down-regulated gene set had been previously linked to anxiety and/or mood disorders (Tab. 1). Among others, these functional classes included potassium ion transport, the neuropeptidergic signaling pathway, nervous system development and the intracellular signaling cascade. The down-regulated gene set was also automatically mapped into previously described pathways using the Pathway Studio software. In accordance with the GO analysis results, the pathway analysis revealed that the down-regulated genes for several neuropeptides and the corresponding adenylate cyclase-cAMP-MAPK, phosphatidyl-inositol- 

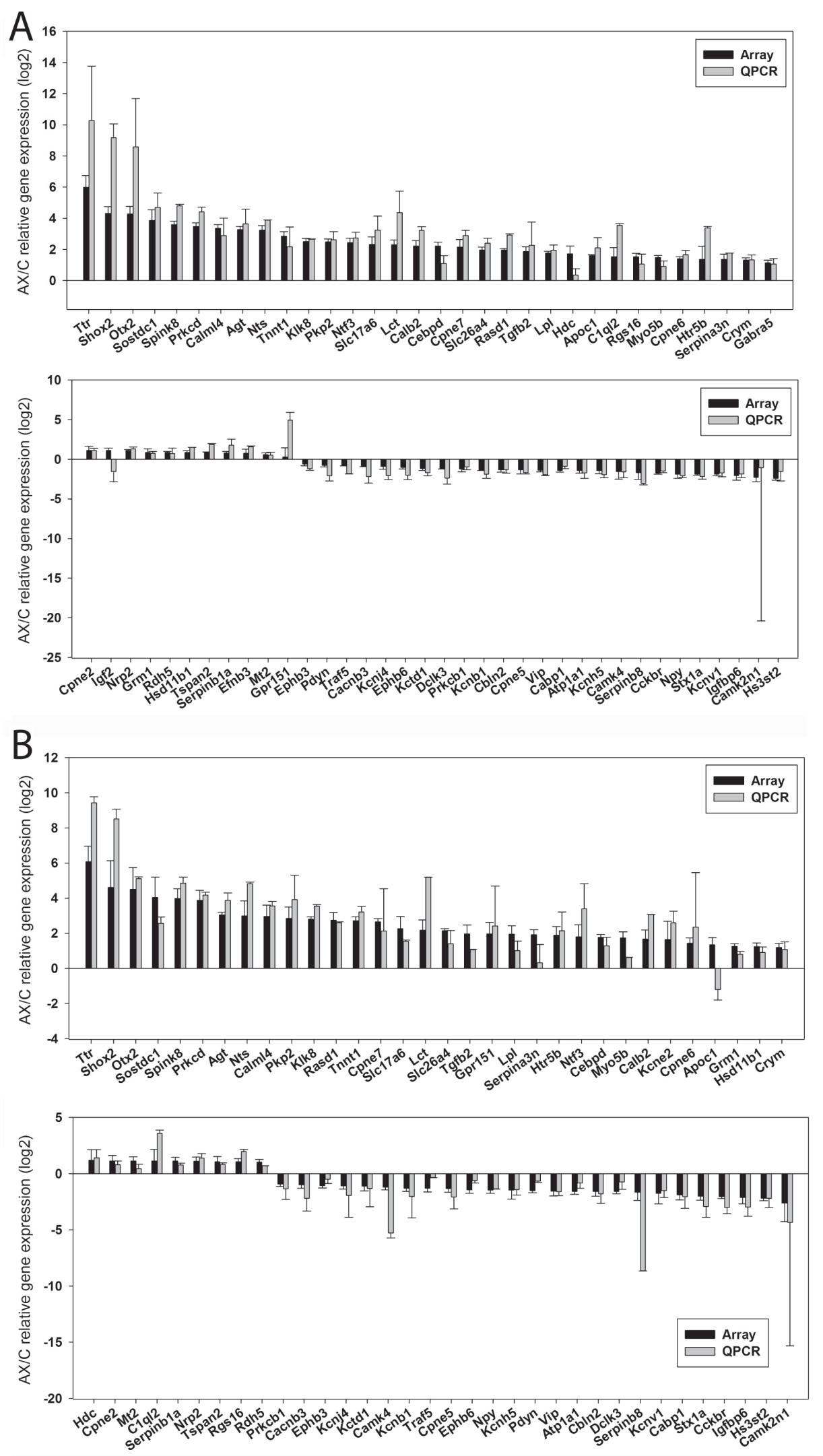

Fig. 3. QPCR validation of microarray data. The pools of RNA from the hippocampus and PCx of AX and control mice were used as templates in the QPCR reaction. The means \pm SD of the AX/control ratio detected by microarray and QPCR are shown for the $(\mathbf{A})$ hippocampus and (B) PCX samples 
Tab. 1. Gene Ontology analysis of microarray data. The significantly up- and down-regulated genes in the hippocampus and/or PCx of AX mice were analyzed for significantly enriched GO functional groups using the DAVID web-based knowledge database. The significantly enriched $(p<0.05)$ functional groups that could be related to anxiety and the corresponding $p$ values are shown

\begin{tabular}{lcl}
\hline Down-regulated genes in AX mice & & \\
\hline Gene Ontology biological function term & p value \\
\hline metal ion transport & 2.18 & $10^{-5}$ \\
Wnt receptor signaling pathway & 5.34 & $10^{-5}$ \\
potassium ion transport & 1.01 & $10^{-4}$ \\
neuropeptidergic signaling pathway & 5.74 & $10^{-4}$ \\
intracellular signaling cascade & 5.57 & $10^{-3}$ \\
nervous system development & 1.47 & $10^{-2}$ \\
regulation of adenylate cyclase activity & 1.76 & $10^{-2}$ \\
synaptic transmission & 2.73 & $10^{-2}$ \\
\hline
\end{tabular}

Up-regulated genes in AX mice

\begin{tabular}{lll}
\hline Gene Ontology biological function term & \multicolumn{2}{c}{$p$ value } \\
\hline nervous system development & 3.58 & $10^{-5}$ \\
behavior & 2.06 & $10^{-4}$ \\
neuron differentiation & 1.90 & $10^{-3}$ \\
regulation of neuron apoptosis & 4.21 & $10^{-3}$ \\
synaptic transmission & 2.04 & $10^{-2}$ \\
cell-cell signaling & 2.07 & $10^{-2}$ \\
neurite development & 2.11 & $10^{-2}$ \\
inorganic anion transport & 3.18 & $10^{-2}$ \\
glial cell differentiation & 4.21 & $10^{-2}$ \\
\hline
\end{tabular}

calcium-calmodulin, protein kinase $\mathrm{A}$, and protein kinase $\mathrm{C}$ downstream signaling members could be grouped into a common pathway (Fig. 4). The upregulated $\mathrm{AX}$ gene set also contained GO biological function classes possibly related to the observed AX phenotype, including nervous system development, behavior and synaptic transmission (Tab. 1).

The DAVID tissue expression database search showed that the expression of 63 genes from the down-regulated gene set had been previously linked to the brain, while 16 had been linked to the brain cortex. Similarly to the down-regulated genes, the DAVID tissue expression database search indicated that the expression of 40 genes from the up-regulated gene set had been previously linked to the brain, and 9 had been linked to the hippocampus. In addition to the QPCR data, the parallel appearance of central nervous system-related functional categories and tissue expression patterns further validated our microarray experiments.

The STRING protein-protein interaction database was used to explore all of the possible connections between the significantly altered genes (Fig. 5). The interaction analysis showed that 93 genes, $61 \%$ of the AX down-regulated gene set, were connected to at least one other gene. The sub-networks at least partially mirrored the GO functional classes described above, such as the Wnt signaling network, the neuropeptidergic network, phosphatidyl-inositol signaling, the calcium signaling networks and the potassium channel network. The STRING analysis also revealed other sub-networks containing immunity-related genes/proteins and Rho-Rac genes involved in cytoskeleton reorganization and trafficking. The STRING interaction analysis of the AX up-regulated gene set showed that 75 genes, $36 \%$ of the AX up-regulated genes, are connected to each other. The extended STRING analysis identified sub-networks related to iodine-thyroxin metabolism, neuropeptidergic signaling, the homeobox network, lipid metabolism and inflammation.

\section{Electrophysiology of hippocampal fEPSP and LTP}

The down-regulation of the voltage-gated potassium channel expression in the AX mice could influence the properties of network excitation and may lead to a net increase in neuronal excitability. In order to investigate this hypothesis, we used in vitro fEPSP recordings from hippocampus slices generated with a multi-electrode array setup (Fig. 6A). The excitability was directly addressed by recording an $\mathrm{I} / \mathrm{O}$ curve from control and AX mice. The AX mice exhibited significantly increased evoked fEPSPs from $30 \mu \mathrm{A}$ $(500 \pm 126 \mu \mathrm{V}$ for $\mathrm{AX}$ mice, $\mathrm{n}=4$, vs. $325 \pm 20 \mu \mathrm{V}$ for controls, $n=4 ; p \leq 0.05$ ). This trend was also observed for the stronger stimulation-evoked fEPSPs $(808 \pm 172 \mu \mathrm{V} v s .472 \pm 32 \mu \mathrm{V}$ at $40 \mu \mathrm{A}, 1057 \pm 215$ $\mu \mathrm{V} v s .602 \pm 44 \mu \mathrm{V}$ at $50 \mu \mathrm{A}, 1253 \pm 252 \mu \mathrm{V} v s .731$ $\pm 57 \mu \mathrm{V}$ at $60 \mu \mathrm{A}$ and $1644 \pm 532 \mu \mathrm{V} v s .956 \pm 67 \mu \mathrm{V}$ at $70 \mu \mathrm{A}$, for the $\mathrm{AX}$ and control mice, respectively).

The observed enhanced excitation in AX mice could lead to impaired LTP in the hippocampus. Therefore, we investigated LTP. The level of thetaburst stimulation (TBS)-evoked LTP was slightly larger than the control 60 min after TBS $(140 \pm 3 \%$ for the AX mice, $n=4 v s .136 \pm 4 \%$ for the control, $\mathrm{n}=4 ; \mathrm{p}=0.08)$. However, the difference was not significant (Fig. 6B). 


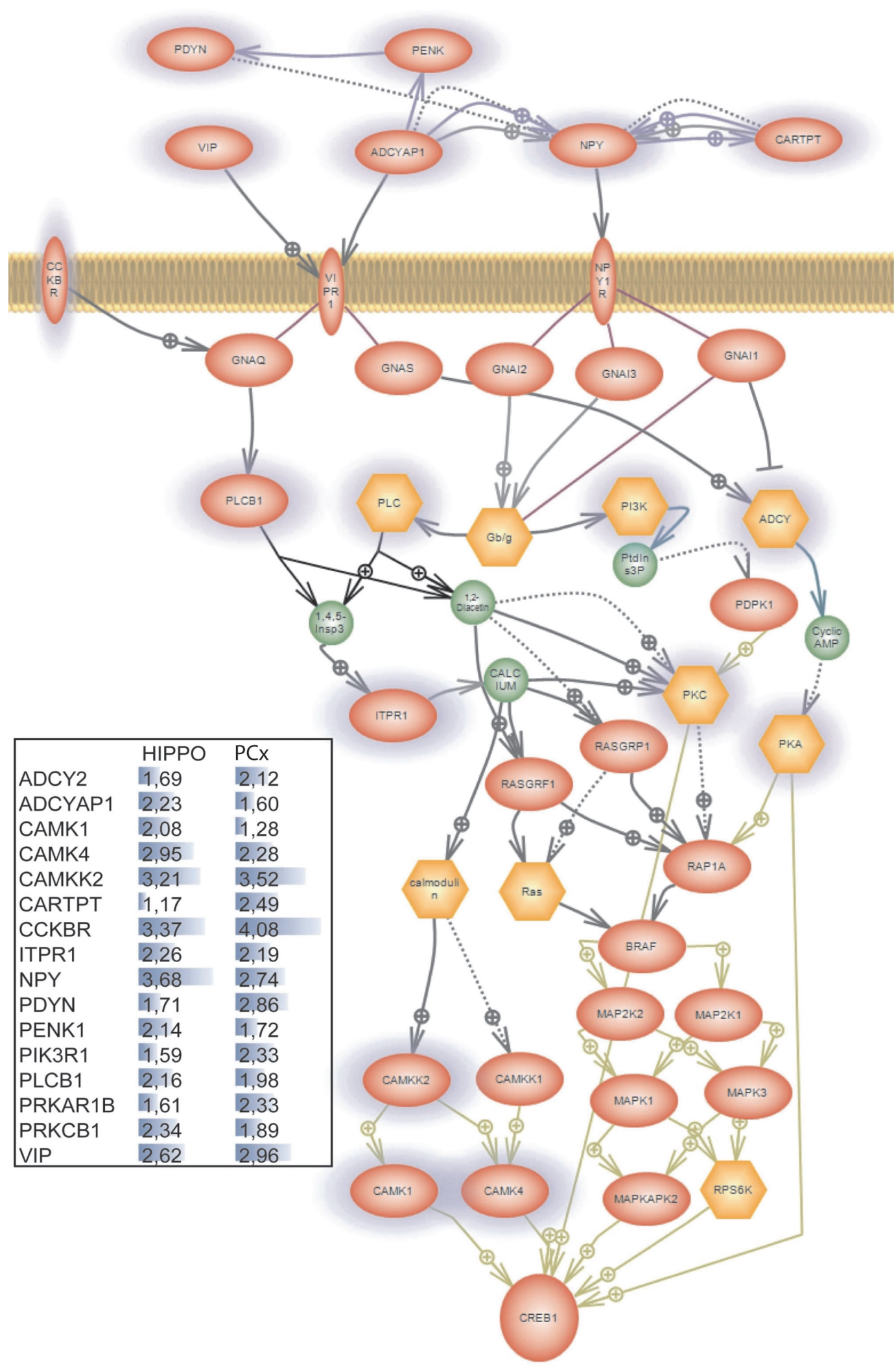

Fig. 4. Molecular network analysis of microarray data. Down-regulation of the neuropeptidergic signaling network in AX mice (See the included Table for gene symbols and level of down-regulation). The significantly repressed genes are highlighted in blue. The fold changes are averages of four independent measurements in each tissue 


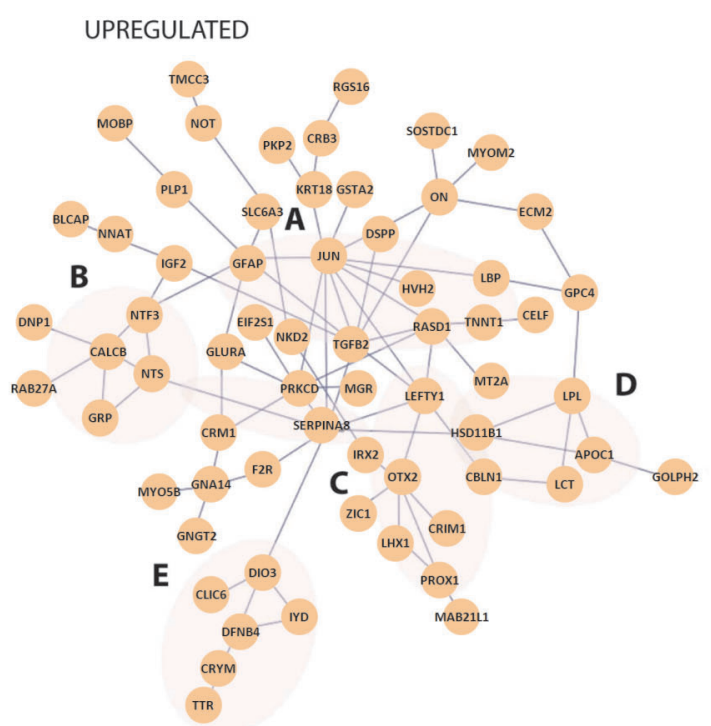

A, INFLAMMATION

\begin{tabular}{|c|c|c|}
\hline & HIPPO & $P C x$ \\
\hline GFAP & 3,03 & $\sqrt{3,44}$ \\
\hline JUN & 2,08 & 1,57 \\
\hline LBP & 1,73 & 3,15 \\
\hline FB2 & 3,66 & $3, \mathrm{c}$ \\
\hline
\end{tabular}

C, DEVELOPMENT

$\begin{array}{lll} & \text { HIPPO } & \text { PCX } \\ \text { IRX2 } & 53,59 & 4,09\end{array}$

LHX1 $\quad[3,02 \quad 5,71$

$\begin{array}{ll}\text { PROX1 } & 5,14\end{array} \mathbf{3 , 1 3}$

$\begin{array}{lll}\text { OTX2 } & 19,55 & 22,76\end{array}$

E, IODINE METABOLISM

$\begin{array}{lll} & \text { HIPPO } & \text { PCX } \\ \text { CLIC6 } & 13,73 & 2,59 \\ \text { CRYM } & 12,49 & 2,28 \\ \text { DIO3 } & 12,73 & 2,11 \\ \text { IYD } & 11,46 & 13,09 \\ \text { TTR } & 163,24 & 67,49\end{array}$

DOWNREGULATED
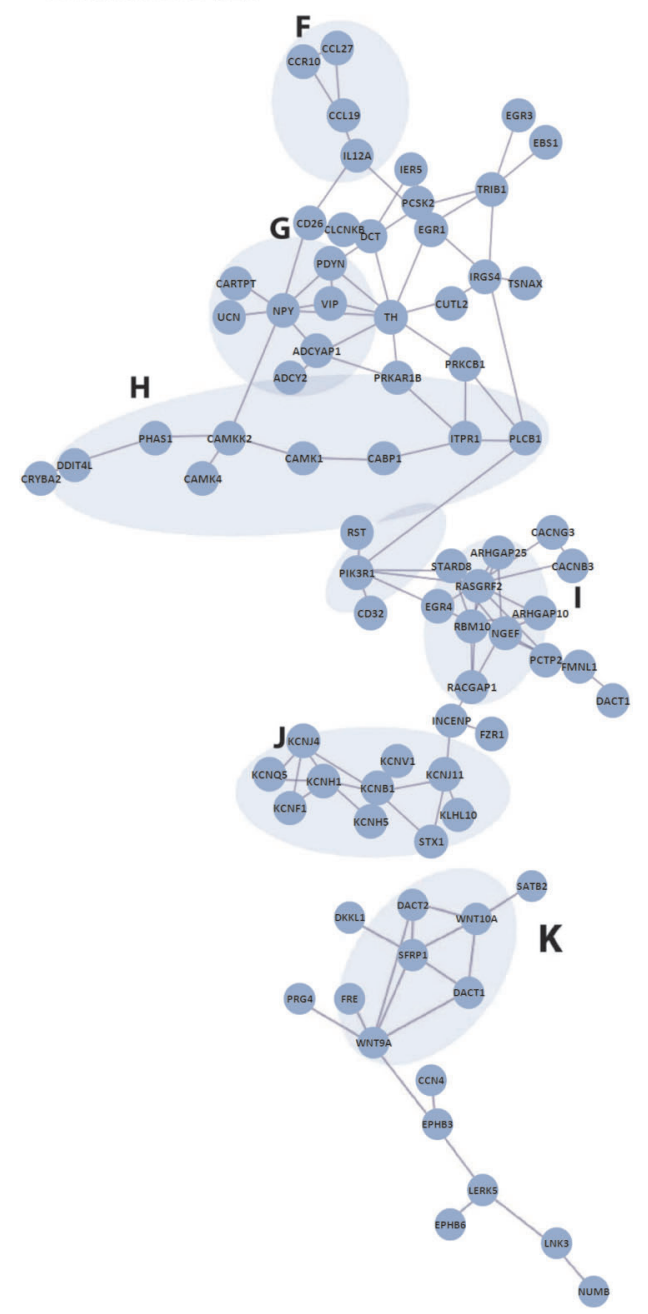

F, CYTOKINES

$\begin{array}{lll} & \text { HIPPO } & \text { PCX } \\ \text { CCBP2 } & 1,96 & 2,11 \\ \text { CCL19 } & 2,90 & 3,10 \\ \text { CCL27 } & 2,41 & 2,13 \\ \text { IL12A } & 2,59 & 2,29\end{array}$

H, SIGNALTRANSDUCTION

$\begin{array}{lll} & \text { HIPPO } & P C X \\ \text { CAMK1 } & 2,08 & 1,28 \\ \text { CABP1 } & 2,66 & 3,71 \\ \text { CAMK4 } & 2,95 & 2,28 \\ \text { CAMKK2 } & 3,21 & 3,52 \\ \text { ITPR1 } & 2,26 & 2,19 \\ \text { PIK3R1 } & 1,59 & 2,33 \\ \text { PLCB1 } & 2,16 & 1,98 \\ \text { PRKAR1B } & 1,61 & 2,33 \\ \text { PRKCB1 } & 2,34 & 1,89\end{array}$

J, POTASSIUM CHANNELS

\begin{tabular}{lll} 
& HIPPO & \multicolumn{1}{c}{$P C x$} \\
\hline KCNB1 & 2,47 & 2,45 \\
KCNF1 & 2,63 & 2,16 \\
KCNH1 & 2,69 & 1,83 \\
KCNH5 & 2,70 & 2,75 \\
KCNJ11 & 1,58 & 2,04 \\
KCNJ4 & 1,86 & 2,12 \\
KCNQ5 & 2,20 & 2,53 \\
KCNV1 & 3,71 & 3,33 \\
KCTD1 & 2,22 & 2,17
\end{tabular}

B, NEUROPEPTIDES

$\begin{array}{lll} & \text { HIPPO } & P C X \\ \text { AGT } & \mathbf{9 , 6 2} & 8,29 \\ \text { CALCB } & 2,36 & 2,30 \\ \text { GRP } & 2,16 & 2,36 \\ \text { NTF3 } & \mathbf{5 , 3 9} & \mathbf{3}, 48 \\ \text { NTS } & \mathbf{9 , 4 4} & \mathbf{1 7 , 9 3}\end{array}$

D, LIPID METABOLISM

HIPPO PCX

$\begin{array}{lll}\mathrm{LPL} & \mathbf{1 , 7 7} \quad 1,94\end{array}$ HSD11B1 l0,85 $\mid 1,25$
G, NEUROPEPTIDES

$\begin{array}{lll} & \text { HIPPO } & \text { PCx } \\ \text { ADCYAP1 } & 2,23 & 1,60 \\ \text { NPY } & 3,68 & 2,74 \\ \text { PDYN } & 1,71 & 2,86 \\ \text { PENK1 } & 2,14 & 1,72 \\ \text { UCN } & 1,62 & 2,03 \\ \text { VIP } & 2,62 & 2,96\end{array}$

\section{I, RHO-RAC NETWORK}

HIPPO PCx ARHGAP25 $2,54 \quad 2,62$ $\begin{array}{lll}\text { NGEF } & 2,82 & 3,12\end{array}$ $\begin{array}{lll}\text { RACGAP } 1 & 1,87 \quad 2,16\end{array}$

Fig. 5. Network analysis of microarray data. Interaction analysis of the up- and down-regulated AX gene sets. The significantly altered genes were analyzed by using the STRING interaction database. The functional groups potentially related to anxiety are highlighted, and the genes relating to the groups are shown with the fold change of up- and down-regulation in the AX hippocampus and PTX vs. controls. The fold changes are averages of four independent measurements in each tissue 
A

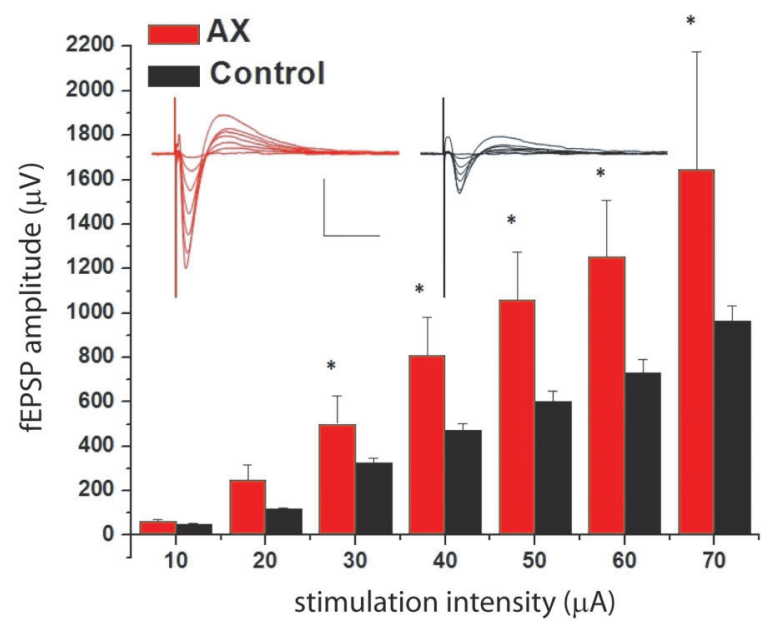

B

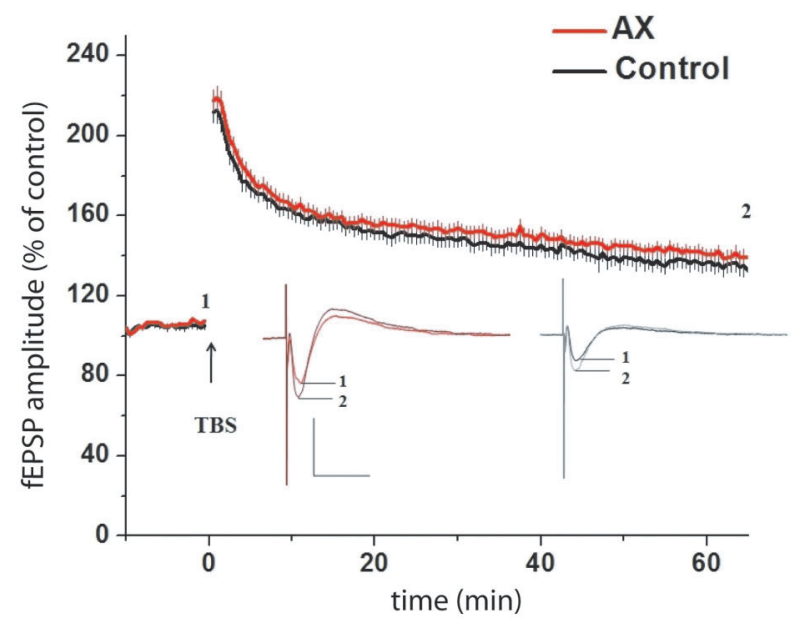

Fig. 6. Input/Output curve and LTP recordings of AX and control hippocampi. (A) Input/Output curve recorded from hippocampi of AX and control mice. Inserts show representative fEPSPs evoked by increasing stimulation intensity (red for AX and black for control mice). Calibration bars are $25 \mathrm{~ms}$ and $1 \mathrm{mV}$. * Significant difference from the control at $\mathrm{p} \leq 0.05$. (B) LTP in hippocampus of the AX and control mice. Inserts show representative fEPSPs recorded at the indicated time points. Note the larger fEPSPs in the AX mouse. Calibration bars are $25 \mathrm{~ms}$ and $1 \mathrm{mV}$

\section{Discussion}

\section{Transcriptome changes in the AX prefrontal cortex and hippocampus}

To investigate the genetic background of anxiety, we applied selection and further breeding of non-anxious control and AX mice [54]. We hypothesized that the resulting clearly distinct phenotypes could provide a valuable basis to study the molecular networks correlated to anxiety [1].

Our transcriptome screen revealed that approximately $2 \%$ of the tested genes were significantly altered in at least one of the brain regions of AX mice compared to controls. The thorough QPCR validation of the microarray data showed a high correlation between the two methods with a low rate of false positives. Functional grouping of the significantly altered genes by GO or STRING-based analysis revealed several functional gene groups that could be associated with the development of anxiety in both brain regions. Functional groups, such as neuropeptides and development-related groups, contained genes from both the AX up- and down-regulated gene sets, while the potassium ion channel group and the intracellular signal transduction group contained predominantly downregulated $\mathrm{AX}$ genes.

\section{Altered neuropeptides and signaling networks}

One of the most prominent gene expression alteration in both brain regions of the AX mice included numerous neuropeptides and members of neuropeptidergic signaling, primarily the phosphatidylinositol-calcium, adenylate cyclase-cAMP-MAPK and calmodulin signaling networks. It is interesting that while neuropeptide genes were both up-regulated and down-regulated, the downstream signaling pathway members were mainly down-regulated. The induced neuropeptides included angiotensinogen, calcitonin-gene related peptide, neurotensin, neurotrophin-3 and gastrin releasing peptide. These up-regulated AX neuropeptides were previously shown to have cerebral location- and concentration-dependent positive or negative effects on fear and anxiety responses [9, 12, 13, 19, 38, 50, 52, 55]. Among the down-regulated AX neuropeptides, prodynorphin and proencephalin displayed an anxiolytic effect in different animal models and anxiety tests [7, 29, 33, 59]. The connection between vasoactive intestinal polypeptide (VIP), downregulated in $\mathrm{AX}$ animals, and anxiety has not been 
well described, but the impact of VIP on behavior was described previously. VIP has been associated with learning- and memory-related behavior [20], social behavior [26], and water and alcohol consumption [32], all behavioral phenotypes that could be related to anxiety. PACAP, a neuropeptide structurally related to VIP, was down-regulated in AX and has also been shown to have an impact on behavior $[43,56]$ and memory retrieval [22]. Neuropeptide Y (NPY), another neuropeptide down-regulated in $\mathrm{AX}$, has been clearly linked to anxiety behavior [8, 25, 44, 47] and the central response to benzodiazepine treatment [24, 28]. It is interesting that there could be an inverse correlation between the NPY concentration and the concentration of transthyretin, the most highly upregulated gene we found in AX mice. It has been previously shown that the NPY concentration was elevated in the forebrain of transthyretin knock-out mice [41], indicating a transthyretin-mediated NPY downregulation. The down-regulation of several signal transduction pathways linked to neuropeptidergic networks were also observed in AX mice. Interestingly, these networks seemed to be downstream effectors of the transduction of VIP-PACAP and NPY. The VIPPACAP system uses the phosphatidylinositol-calcium-calmodulin signaling pathways and the adenylate cyclase-cAMP-PKA-MAPK networks, while NPY signals through the phosphatidylinositol-calcium-calmodulin network. The phosphatidylinositol-calcium signaling converges into the calmodulincalmodulin kinase network, which targets, among others, the cAMP response element binding (CREB) transcription factor [15]. CREB is a common target of the two signaling pathways. The adenylate cyclase-cAMP signaling also targets CREB through the MAP-MAPK network $[15,60]$. It is noteworthy that, in addition to the involvement in the CREB pathway, adenylate cyclase signaling has been associated with the anxiety phenotype $[17,31,49]$. CREB is a central transcription factor involved in different behavioral processes and phenotypes, such as memory [34], induction of LTP [10], synaptic plasticity [36] and depression [4, 40, 57]. The connection between CREB activity and anxiety has also been previously described in different model systems [5, 6]. Overall, our results indicate that the decreased CREB activation might be involved in the initiation of anxiety in our animal model.

\section{Anxiety-related changes of ion channel and receptor expression}

One striking feature of the mRNA expression pattern was the down-regulation of a large number of ion channels, particularly potassium ion channels, in AX mice. The significance of the enrichment of the metal ion transport GO biological function category was $\mathrm{p}=$ 0.00002 with 17 repressed genes, while the potassium channels category had a significance level of $p=0.0001$ with 10 genes down-regulated. Among these channels, only a few have been characterized functionally in relation to neural excitability and/or anxiety. The AX down-regulated potassium channel, the voltagegated KQT-like subfamily member 5 (KCNQ5), is a member of the KCNQ family that encodes the Kv7 potassium channel subunits. Kv7 channels are involved in decreasing excitability [23], and Kv7 channel openers have been successfully applied in unconditioned and conditioned rodent models of anxiety [30]. The down-regulated potassium voltage-gated channel, Shab-related subfamily member 1 (KCNB1) potassium channel, is a key mediator of the delayed rectifier $\mathrm{Kv}$ currents regulating neuronal excitability [39]. The AX down-regulated KCNJ4 potassium channel has also been shown to play a role in decreasing neural excitability in rat primary striatal cultures [18]. In addition to the various potassium channels, the delta subunit of the inhibitory GABA-A receptor was also down regulated in the AX mice, which also pointed to an imbalance between inhibition and excitation. In support of the increased excitability hypothesis, both the AMPA type ionotropic glutamate receptor GRIA1 and the group I metabotropic glutamate receptor GRM1 were found to be up-regulated in both brain regions in AX mice. The involvement of ionotropic AMPA glutamate receptors and group I metabotropic glutamate receptors have also been described in different models of anxiety $[11,14]$.

Altogether, the above-mentioned results highlighted the possibility that the neural excitability in the PCX and hippocampus increased in the AX mice. We addressed the increased neuronal excitability hypothesis directly using electrophysiology in hippocampal slices. The excitability (fEPSP) was significantly greater in the $\mathrm{AX}$ mice than in the control strain, illustrating that the changes in the mRNA levels were reflected in the phenotype. However, LTP was intact, suggesting that higher cognitive functions were not impaired in the AX mice. Our results indi- 
cate that, in addition to the already described increased amygdalar excitability $[46,48]$, elevated hippocampal excitability also correlates with the anxiety phenotype.

\section{Conclusions}

In accordance with the multigenic nature of anxiety, our transcription analysis of the AX hippocampus and PCx clearly revealed that several genes with different functions and from various pathways may be involved in the generation of the observed phenotype. One of the major questions is whether the observed alteration of gene expression is a cause or an effect of anxiety. Most likely, both mechanisms are involved in our model. Pathways, such as the potassium channel network, the neuropeptidergic system and the corresponding signaling pathways, can have a causative role in anxiety development, while others, such as the inflammation-immunity related genes, may be a result of the stress-related immune function modulation. Our analysis served as a first screening approach. The characterization of particular genes in the development of anxiety requires more focused studies using targeted loss of function or gain of function approaches.

\section{Acknowledgments:}

Dezso P. Virok and Viktor Szegedi were supported by the Ede Teller Program of the National Office for Research and Technology (NAP_BIO_06). Agnes Zvara was supported by the János Bolyai Fellowship of the Hungarian Academy of Sciences (BO/00381/07). This work was supported by the National Office for Research and Technology (NKTH RET-08/2004) and TAMOP-4.2.2.-08/1-20080002. Botond Penke, Tamás Janáky, Gábor Juhász were supported by Hungarian Scientific Research Fund (OTKA NK 73672) and the European Commission (FP-7 201 159).

\section{Conflict of interest}

Authors declare no competing financial interests in relation to the presented work.

\section{References:}

1. Andrade EC, Krueger DD, Nairn AC: Recent advances in neuroproteomics. Curr Opin Mol Ther, 2007, 9, 270-281.

2. Ansseau M, Dierick M, Buntinkx F, Cnockaert P, De Smedt J, Van Den Haute M, Vander Mijnsbrugge D:
High prevalence of mental disorders in primary care. J Affect Disord, 2004, 78, 49-55.

3. Bannerman DM, Rawlins JN, McHugh SB, Deacon RM, Yee BK, Bast T, Zhang WN et al.: Regional dissociations within the hippocampus-memory and anxiety. Neurosci Biobehav Rev, 2004, 28, 273-283.

4. Barad M, Bourtchouladze R, Winder DG, Golan H, Kandel E: Rolipram, a type IV-specific phosphodiesterase inhibitor, facilitates the establishment of longlasting long-term potentiation and improves memory. Proc Natl Acad Sci USA, 1998, 95, 15020-15025.

5. Barrot M, Olivier JD, Perrotti LI, DiLeone RJ, Berton O, Eisch AJ, Impey S et al.: CREB activity in the nucleus accumbens shell controls gating of behavioral responses to emotional stimuli. Proc Natl Acad Sci USA, 2002, 99, 11435-11440.

6. Barrot M, Wallace DL, Bolanos CA, Graham DL, Perrotti LI, Neve RL, Chambliss $\mathrm{H}$ et al.: Regulation of anxiety and initiation of sexual behavior by CREB in the nucleus accumbens. Proc Natl Acad Sci USA, 2005, 102, 8357-8362.

7. Bilkei-Gorzo A, Racz I, Michel K, Zimmer A, Klingmuller D: Behavioral phenotype of pre-proenkephalindeficient mice on diverse congenic backgrounds. Psychopharmacology (Berl), 2004, 176, 343-352.

8. Broqua P, Wettstein JG, Rocher MN, Gauthier-Martin B, Junien JL: Behavioral effects of neuropeptide Y receptor agonists in the elevated plus-maze and fear-potentiated startle procedures. Behav Pharmacol, 1995, 6, 215-222.

9. Catts VS, Al-Menhali N, Burne TH, Colditz MJ, Coulson EJ: The p75 neurotrophin receptor regulates hippocampal neurogenesis and related behaviours. Eur J Neurosci, 2008, 28, 883-892.

10. Cha-Molstad H, Keller DM, Yochum GS, Impey S, Goodman RH: Cell-type-specific binding of the transcription factor CREB to the cAMP-response element. Proc Natl Acad Sci USA, 2004, 101, 13572-13577.

11. Chojnacka-Wojcik E, Klodzinska A, Pilc A: Glutamate receptor ligands as anxiolytics. Curr Opin Investig Drugs, 2001, 2, 1112-1119.

12. Chourbaji S, Brandwein C, Vogt MA, Dormann C, Hellweg R, Gass P: Nature vs. nurture: can enrichment rescue the behavioural phenotype of BDNF heterozygous mice? Behav Brain Res, 2008, 192, 254-258.

13. Costall B, Domeney AM, Gerrard PA, Horovitz ZP, Kelly ME, Naylor RJ, Tomkins DM: Effects of captopril and SQ29,852 on anxiety-related behaviours in rodent and marmoset. Pharmacol Biochem Behav, 1990, 36, 13-20.

14. Das P, Lilly SM, Zerda R, Gunning WT, 3rd, Alvarez FJ, Tietz EI: Increased AMPA receptor GluR1 subunit incorporation in rat hippocampal CA1 synapses during benzodiazepine withdrawal. J Comp Neurol, 2008, 511, 832-846.

15. Dash PK, Karl KA, Colicos MA, Prywes R, Kandel ER: cAMP response element-binding protein is activated by $\mathrm{Ca}^{2+} /$ calmodulin- as well as cAMP-dependent protein kinase. Proc Natl Acad Sci USA, 1991, 88, 5061-5065.

16. de Mooij-van Malsen AJ, Olivier B, Kas MJ: Behavioural genetics in mood and anxiety: a next step in find- 
ing novel pharmacological targets. Eur J Pharmacol, 2008, 585, 436-440.

17. de Mooij-van Malsen AJ, van Lith HA, Oppelaar H, Hendriks J, de Wit M, Kostrzewa E, Breen G et al.: Interspecies trait genetics reveals association of Adcy8 with mouse avoidance behavior and a human mood disorder. Biol Psychiatry, 2009, 66, 1123-1130.

18. Falk T, Xie JY, Zhang S, Kennedy J, Bennett J, Yool AJ, Sherman SJ: Over-expression of the potassium channel Kir2.3 using the dopamine-1 receptor promoter selectively inhibits striatal neurons. Neuroscience, 2008, 155, 114-127.

19. Georgiev V, Stancheva S, Kambourova T, Getova D: Effect of angiotensin II on the Vogel conflict paradigm and on the content of dopamine and noradrenaline in rat brain. Acta Physiol Pharmacol Bulg, 1990, 16, 32-37.

20. Glowa JR, Panlilio LV, Brenneman DE, Gozes I, Fridkin M, Hill JM: Learning impairment following intracerebral administration of the HIV envelope protein gp120 or a VIP antagonist. Brain Res, 1992, 570, 49-53.

21. Greenberg PE, Sisitsky T, Kessler RC, Finkelstein SN, Berndt ER, Davidson JR, Ballenger JC, Fyer AJ: The economic burden of anxiety disorders in the 1990s. J Clin Psychiatry, 1999, 60, 427-435.

22. Hagino N: Performance of PAC1-R heterozygous mice in memory tasks-II. J Mol Neurosci, 2008, 36, 208-219.

23. Hansen HH, Waroux O, Seutin V, Jentsch TJ, Aznar S, Mikkelsen JD: Kv7 channels: interaction with dopaminergic and serotonergic neurotransmission in the CNS. J Physiol, 2008, 586, 1823-1832.

24. Heberlein A, Bleich S, Kornhuber J, Hillemacher T: Neuroendocrine pathways in benzodiazepine dependence: new targets for research and therapy. Hum Psychopharmacol, 2008, 23, 171-181.

25. Heilig M, McLeod S, Koob GK, Britton KT: Anxiolytic-like effect of neuropeptide Y (NPY), but not other peptides in an operant conflict test. Regul Pept, 1992, 41, 61-69.

26. Hill JM, Hauser JM, Sheppard LM, Abebe D, SpivakPohis I, Kushnir M, Deitch I, Gozes I: Blockage of VIP during mouse embryogenesis modifies adult behavior and results in permanent changes in brain chemistry. J Mol Neurosci, 2007, 31, 183-200.

27. Jensen LJ, Kuhn M, Stark M, Chaffron S, Creevey C, Muller J, Doerks T et al.: STRING 8 - a global view on proteins and their functional interactions in 630 organisms. Nucleic Acids Res, 2008.

28. Kask A, Rago L, Harro J: Anxiogenic-like effect of the neuropeptide Y Y1 receptor antagonist BIBP3226: antagonism with diazepam. Eur J Pharmacol, 1996, 317, R3-4.

29. Konig M, Zimmer AM, Steiner H, Holmes PV, Crawley JN, Brownstein MJ, Zimmer A: Pain responses, anxiety and aggression in mice deficient in pre-proenkephalin. Nature, 1996, 383, 535-538.

30. Korsgaard MP, Hartz BP, Brown WD, Ahring PK, Strobaek D, Mirza NR: Anxiolytic effects of Maxipost (BMS-204352) and retigabine via activation of neuronal Kv7 channels. J Pharmacol Exp Ther, 2005, 314, 282-292.

31. Krishnan V, Graham A, Mazei-Robison MS, Lagace DC, Kim KS, Birnbaum S, Eisch AJ et al.: Calcium-sensitive adenylyl cyclases in depression and anxiety: behavioral and biochemical consequences of isoform targeting. Biol Psychiatry, 2008, 64, 336-343.

32. Kulkosky PJ, Doyle JS, Cook VI, Glazner GW, Foderaro MA: Vasoactive intestinal peptide: behavioral effects in the rat and hamster. Pharmacol Biochem Behav, 1989, 34, 387-393.

33. Kuzmin A, Madjid N, Terenius L, Ogren SO, Bakalkin G: Big dynorphin, a prodynorphin-derived peptide produces NMDA receptor-mediated effects on memory, anxiolytic-like and locomotor behavior in mice. Neuropsychopharmacology, 2006, 31, 1928-1937.

34. Kwok RP, Lundblad JR, Chrivia JC, Richards JP, Bachinger HP, Brennan RG, Roberts SG et al.: Nuclear protein CBP is a coactivator for the transcription factor CREB. Nature, 1994, 370, 223-226.

35. Lobenhofer EK, Bushel PR, Afshari CA, Hamadeh HK: Progress in the application of DNA microarrays. Environ Health Perspect, 2001, 109, 881-891.

36. Marie H, Morishita W, Yu X, Calakos N, Malenka RC: Generation of silent synapses by acute in vivo expression of CaMKIV and CREB. Neuron, 2005, 45, 741-752.

37. Mirnics K, Levitt P, Lewis DA: Critical appraisal of DNA microarrays in psychiatric genomics. Biol Psychiatry, 2006, 60, 163-176.

38. Mountney C, Sillberg V, Kent P, Anisman H, Merali Z: The role of gastrin-releasing peptide on conditioned fear: differential cortical and amygdaloid responses in the rat. Psychopharmacology (Berl), 2006, 189, 287-296.

39. Murakoshi H, Trimmer JS: Identification of the Kv2.1 $\mathrm{K}+$ channel as a major component of the delayed rectifier $\mathrm{K}+$ current in rat hippocampal neurons. J Neurosci, 1999, 19, 1728-1735.

40. Nibuya M, Nestler EJ, Duman RS: Chronic antidepressant administration increases the expression of cAMP response element binding protein (CREB) in rat hippocampus. J Neurosci, 1996, 16, 2365-2372.

41. Nunes AF, Saraiva MJ, Sousa MM: Transthyretin knockouts are a new mouse model for increased neuropeptide Y. FASEB J, 2006, 20, 166-168.

42. Puskas LG, Bereczki E, Santha M, Vigh L, Csanadi G, Spener F, Ferdinandy P et al.: Cholesterol and cholesterol plus DHA diet-induced gene expression and fatty acid changes in mouse eye and brain. Biochimie, 2004, 86, 817-824.

43. Reglodi D, Kiss P, Tamas A, Lengvari I: The effects of PACAP and PACAP antagonist on the neurobehavioral development of newborn rats. Behav Brain Res, 2003, 140, 131-139.

44. Roy A, Pandey SC: The decreased cellular expression of neuropeptide $\mathrm{Y}$ protein in rat brain structures during ethanol withdrawal after chronic ethanol exposure. Alcohol Clin Exp Res, 2002, 26, 796-803.

45. Saeed AI, Sharov V, White J, Li J, Liang W, Bhagabati N, Braisted J et al.: TM4: a free, open-source system for microarray data management and analysis. Biotechniques, 2003, 34, 374-378.

46. Sajdyk TJ, Shekhar A: Excitatory amino acid receptor antagonists block the cardiovascular and anxiety responses elicited by $\gamma$-aminobutyric acid $_{\mathrm{A}}$ receptor block- 
ade in the basolateral amygdala of rats. J Pharmacol Exp Ther, 1997, 283, 969-977.

47. Sajdyk TJ, Vandergriff MG, Gehlert DR: Amygdalar neuropeptide Y Y1 receptors mediate the anxiolytic-like actions of neuropeptide $\mathrm{Y}$ in the social interaction test. Eur J Pharmacol, 1999, 368, 143-147.

48. Sanders SK, Shekhar A: Regulation of anxiety by $\mathrm{GABA}_{\mathrm{A}}$ receptors in the rat amygdala. Pharmacol Biochem Behav, 1995, 52, 701-706.

49. Schaefer ML, Wong ST, Wozniak DF, Muglia LM, Liauw JA, Zhuo M, Nardi A et al.: Altered stressinduced anxiety in adenylyl cyclase type VIII-deficient mice. J Neurosci, 2000, 20, 4809-4820.

50. Shepherd J, Bill DJ, Dourish CT, Grewal SS, McLenachan A, Stanhope KJ: Effects of the selective angiotensin II receptor antagonists losartan and PD123177 in animal models of anxiety and memory. Psychopharmacology (Berl), 1996, 126, 206-218.

51. Sherman BT, Huang da W, Tan Q, Guo Y, Bour S, Liu D, Stephens R et al.: DAVID Knowledgebase: a genecentered database integrating heterogeneous gene annotation resources to facilitate high-throughput gene functional analysis. BMC Bioinformatics, 2007, 8, 426.

52. Shilling PD, Feifel D: The neurotensin-1 receptor agonist PD149163 blocks fear-potentiated startle. Pharmacol Biochem Behav, 2008, 90, 748-752.

53. Smoller JW, Faraone SV: Genetics of anxiety disorders: complexities and opportunities. Am J Med Genet C Semin Med Genet, 2008, 148C, 85-88.

54. Szego EM, Janaky T, Szabo Z, Csorba A, Kompagne H, Muller G, Levay G et al.: A mouse model of anxiety molecularly characterized by altered protein networks in the brain proteome. Eur Neuropsychopharmacol, 2010, 96-111.

55. Tashev R, Belcheva S, Milenov K, Belcheva I: Behavioral effects of somatostatin microinjected into caudate putamen. Neuropeptides, 2001, 35, 271-275.

56. Telegdy G, Kokavszky K: The action of pituitary adenylate cyclase activating polypeptide (PACAP) on passive avoidance learning. The role of transmitters. Brain Res, 2000, 874, 194-199.

57. Wallace TL, Stellitano KE, Neve RL, Duman RS: Effects of cyclic adenosine monophosphate response element binding protein overexpression in the basolateral amygdala on behavioral models of depression and anxiety. Biol Psychiatry, 2004, 56, 151-160.

58. Wesołowska A: Potential role of the $5-\mathrm{HT}_{6}$ receptor in depression and anxiety: an overview of preclinical data. Pharmacol Rep, 2010, 62, 564-577.

59. Wittmann W, Schunk E, Rosskothen I, Gaburro S, Singewald N, Herzog H, Schwarzer C: Prodynorphin-derived peptides are critical modulators of anxiety and regulate neurochemistry and corticosterone. Neuropsychopharmacology, 2009, 34, 775-785.

60. Xing J, Ginty DD, Greenberg ME: Coupling of the RASMAPK pathway to gene activation by RSK2, a growth factor-regulated CREB kinase. Science, 1996, 273, 959-963.

Received: May 4, 2010; in the revised form: October 6, 2010; accepted: November 13, 2010. 